\title{
Multiple etiologies of infectious diarrhea and concurrent infections in a pediatric outpatient-based screening study in Odisha, India
}

\author{
Arpit Kumar Shrivastava ${ }^{1}$, Subrat Kumarr ${ }^{1}$ Nirmal Kumar Mohakud ${ }^{2}$, Mrutyunjay Suar $^{1}$ \\ and Priyadarshi Soumyaranjan Sahu ${ }^{1,2,3^{*}}$
}

\begin{abstract}
Background: There are multiple etiologies responsible for infectious gastroenteritis causing acute diarrhea which are often under diagnosed. Also acute diarrhea is one of the major causes of morbidity and mortality among children less than 5 years of age.

Methods: In our study, fecal samples $(n=130)$ were collected from children $(<5$ years) presenting with symptoms of acute diarrhea. Samples were screened for viral, bacterial, and parasitic etiologies. Rotavirus and Adenovirus were screened by immunochromatographic tests. Diarrheagenic Escherichia coli (EPEC, EHEC, STEC, EAEC, O157, O111), Shigella spp., Salmonella spp., Vibrio cholera, Cryptosporidium spp., and Giardia spp. were detected by gene-specific polymerase chain reaction.

Results: Escherichia coli was detected to be the major etiological agent (30.07\%) followed by Rotavirus (26.15\%), Shigella (23.84\%), Adenovirus (4.61\%), Cryptosporidium (3.07\%), and Giardia (0.77\%). Concurrent infections with two or more pathogens were observed in 44 of 130 (33.84\%) cases with a predominant incidence particularly in <2-year-old children (65.90\%) compared to children of 2-5 years age group (34.09\%). An overall result showed significantly higher detection rates among children with diarrhea in both combinations of two as well as three infections concurrently ( $p=0.004915$ and 0.03917 , respectively).

Conclusion: Suspecting possible multiple infectious etiologies and diagnosis of the right causative agent(s) can aid in a better pharmacological management of acute childhood diarrhea. It is hypothesized that in cases with concurrent infections the etiological agents might be complementing each other's strategies of pathogenesis resulting in severe diarrhea that could be studied better in experimental infections.
\end{abstract}

Keywords: Diarrhea, Infectious diarrhea, Children, Concurrent infection, Co-infection, Odisha

\section{Background}

Global and national estimates clearly indicate that diarrheal disease is a major public health concern $[1,2]$. According to the World Health Organization (WHO), diarrheal diseases are the second leading cause of death

\footnotetext{
*Correspondence: priyadarshi_sahu@yahoo.com;

Priyadarshi@imu.edu.my

${ }^{3}$ Divisions of Pathology, School of Medicine, International Medical

University, 57000 Kuala Lumpur, Malaysia

Full list of author information is available at the end of the article
}

$(\sim 760,000$ per year) in children $<5$ years of age. Recent studies suggested that diarrheal diseases are the leading cause of childhood deaths in developing countries. Infectious agents, viz., viruses (Rotavirus, Adenovirus, Hepatitis A\&E, Norwalk), bacteria (E. coli, Salmonella, Shigella, Vibrio), protozoa (Giardia, Cryptosporidium, Cyclospora, Microsporidia, Isospora), etc., are usually responsible for serious diarrheal disease outbreaks [3-5]. Among these pathogens, diarrheagenic E. coli (DEC), Rotavirus, and 
Shigella spp. are the major contributors of childhood morbidity and mortality [6-8].

Globally Rotavirus is responsible for around 0.5 million-child deaths annually [9], while national estimates from India showed that Rotavirus is responsible for almost 0.1 million deaths, $0.4-0.8$ million hospitalization, and 2 million outpatient visits in children $<5$ years of age [10]. Among DECs, enteropathogenic E. coli (EPEC) strain accounts for $5-10 \%$ of pediatric diarrhea in resource-poor countries [11]. Shigellosis, caused by enteroinvasive E. coli or Shigella spp., plays an important role in morbidity and mortality among children $<5$ years of age. About 125 million cases of endemic shigellosis occur every year in Asian countries [12, 13].

Also past studies from developing countries suggest Cryptosporidium to be the leading cause of parasitic diarrhea among children [3, 14], while Giardia infects 200 million people each year in developing countries such as Africa, Asia and Latin America [15]. Various studies have elucidated the prevalence of different etiological agents in children with diarrhea [16-18].

Poor hygiene and sanitation condition increases the transmission dynamics of diarrheal diseases in community settings. All these diarrheal agents are transmitted either through contaminated food, water, or through the fecal oral route. However, there are limited numbers of studies focusing on multiple etiologies particularly in children with diarrhea $[19,20]$.

Concurrent infection with more than single pathogen might be common among children with diarrhea. Also multiple infections of diarrheal pathogens might cause more severe diarrhea compared to infection with a single pathogen, thereby complicating the treatment management procedures $[17,21]$. Due to scarcity of reports on concurrent infections causing diarrhea among children from the studied province in India, we attempted to estimate the overall burden of major diarrheal pathogens and possible concurrent infections with multiple infectious agents among children in a hospital-based screening study.

\section{Methods}

\section{Study design}

This study was conducted in a tertiary care teaching hospital in Bhubaneswar, Odisha (India). Fecal samples were collected from 130 children from June 2015 to April 2016. Stool samples were collected from children considering the inclusion and exclusion criteria. Inclusion criteria were children less than 5 years of age and 3 or more than 3 diarrheal episodes in a day. Children having malabsorption, immunocompromised individuals, and patients who have undergone immune suppressive therapy and prolonged steroid treatment were excluded from our study.
Fecal samples were also collected from 48 non-diarrheal children less than 5 years of age, which acted as a control group. The study protocol was reviewed and approved by the Institutional Ethics Committee. Informed consent and patient datasheets were maintained for each participant.

\section{Sample collection and DNA extraction}

From each of these participants, fecal samples were collected in a sterile vial. Samples were placed on ice and transported to lab within $4 \mathrm{~h}$ and processed immediately. Total fecal genomic DNA was extracted from stool using QIAamp Fast DNA stool Mini Kit (Qiagen, Germany) according to the manufacturer's instruction. The quantity and purity of extracted DNA were measured using a Nanodrop (Epoch BioTek, USA).

Extracted DNA samples were stored at $-20{ }^{\circ} \mathrm{C}$ until further processing. Bacterial genomic DNA was isolated from pure cultures of $S$. enterica subsp., serovar typhimurium, V. cholera, S. flexneri, and E. coli (from the repository) using blood and tissue genomic DNA isolation kit (Qiagen, Germany) as per the manufacturer's protocol. These were used as positive controls for pathogen detection by polymerase chain reaction (PCR).

\section{Immunochromatographic test for detecting viral pathogen} Fecal specimens were screened for the presence of Rotavirus and Adenovirus by using immunochromatographic test (Combi-Strip C-1004, Coris Bioconcept ltd-Belgium) in accordance with the manufacturer's instructions. This is a rapid diagnostic test based on homogenous membrane system with colloidal gold particles. The test was carried out as described previously [22].

\section{PCR assay for detecting bacterial and parasitic pathogens}

Fecal genomic DNA extracted from stool was used as a template in a series of PCR amplification reactions using primers specific for each pathogen (Table 1). Bacteria-specific genomic DNA isolated from pure cultures was used as a positive amplification control in PCR screening. For detecting protozoan parasites, positive DNA control for Cryptosporidium was obtained from Christian Medical College, Vellore (India), while standard Giardia DNA was obtained from the Institute of Parasitology, University of Zurich. PCR cycling conditions for different bacterial and protozoan parasites were as follows: Initial denaturation at $95{ }^{\circ} \mathrm{C}$ for $5 \mathrm{~min}$, followed by 34 cycles of denaturation of $94{ }^{\circ} \mathrm{C}$ for $30 \mathrm{~s}$, annealing at primer-specific temperature at 30-45 s and extension at $72{ }^{\circ} \mathrm{C}$ for $1 \mathrm{~min}$, and final extension for $72{ }^{\circ} \mathrm{C}$ for $7 \mathrm{~min}$. All PCR products were subjected to $1-1.5 \%$ agarose gel electrophoresis to confirm positive samples. 
Table 1 Detailed description of pathogen-specific polymerase chain reaction primers for their specific detection in stool

\begin{tabular}{|c|c|c|c|c|c|c|}
\hline Pathogen & Target gene & Primer name & Primer sequence $\left(5^{\prime}\right.$ to $\left.3^{\prime}\right)$ & $\operatorname{Tm}\left({ }^{\circ} \mathrm{C}\right)$ & Size (bp) & References \\
\hline \multicolumn{7}{|c|}{ Escherichia coli } \\
\hline \multirow[t]{2}{*}{ EAEC } & EAEC pCVD432 & EAEC_pCVD432_F_11 & CTGGCGAAAGACTGTATCAT & 51 & 630 & [23] \\
\hline & & EAEC_pCVD432_R_12 & AAATGTATAGAAATCCGCTGTT & & & \\
\hline \multirow[t]{2}{*}{ EPEC } & EPEC bfpA & EPEC_bfpA_F_9 & TTCTTGGTGCTTGCGTGTCTTTT & 53 & 367 & [23] \\
\hline & & EPEC_bfpA_F_10 & TITTGTTTGTTGTATCTTTGTAA & & & \\
\hline \multirow[t]{2}{*}{ EPEC } & EPEC eae gene & EPEC_eaeA_F & GACCCGGCACAAGCATAAGC & 59 & 384 & [24] \\
\hline & & EPEC_eaeA_R & CCACCTGCAGCAACAAGAGG & & & \\
\hline \multirow[t]{2}{*}{ STEC } & EHEC vt1 & EHEC_vt2_R_7 & ACCGTTTTTCAGATTTT(G/A)CACATA & 52 & 298 & [23] \\
\hline & & EHEC_vt2_R_8 & TACACAGGAGCAGTTTCAGACAGT & & & \\
\hline \multirow[t]{2}{*}{ STEC } & EHEC hlyA gene & EHEC_hlyA_F & GCATCATCAAGCGTACGTTCC & 57 & 534 & [24] \\
\hline & & EHEC_hlyA_R & AATGAGCCAAGCTGGTTAAGCT & 54 & 180 & \\
\hline \multirow[t]{2}{*}{ STEC } & stx1 & E. coli_st $1 \mathrm{~F}$ & ATAAATCGCCATTCGTTGACTAC & & & [24] \\
\hline & & E. coli_st $1 \mathrm{1R}$ & GGCACTGTCTGAAACTGCTCC & & & \\
\hline \multirow[t]{2}{*}{ STEC } & stx2 & E. coli_st $\times 2 \mathrm{~F}$ & GGCACTGTCTGAAACTGCTCC & 56 & 255 & [24] \\
\hline & & E. coli_st $\times 2 R$ & TCGCCAGTTATCTGACATTCTG & & & \\
\hline \multirow[t]{2}{*}{ STEC } & $\mathrm{rfbE} 157: \mathrm{H7}$ & O157_F & CGGACATCCATGTGATATGG & 52 & 259 & [24] \\
\hline & & O157_R & TTGCCTATGTACAGCTAATCC & & & \\
\hline \multirow[t]{2}{*}{ STEC } & H7 FLIC & H7_FLIC-R_13 & GCGCTGTCGAGTTCTATCGAGC & 59 & 625 & [23] \\
\hline & & H7_FLIC-R_14 & CAACGGTGACTTATCGCCATTCC & & & \\
\hline \multirow[t]{2}{*}{ STEC } & O111 rfb region & O111_F & TAGAGAAATTATCAAGTTAGTTCC & 49 & 406 & [24] \\
\hline & & O111_R & ATAGTTATGAACATCTTGTTTAGC & & & \\
\hline \multicolumn{7}{|c|}{ Shigella spp. } \\
\hline & ShET 1 & Shigella_1A_F & CAG CGT CTTTCA GCG ACA GTG TTT & 57 & 530 & [8] \\
\hline & & Shigella_1A_R & AGC ATG ATA CTC AAC AGC CAG ACC & & & \\
\hline & & Shigella_1B_F & ATA CTG GCT CCT GTC ATT CAC GGT & & & \\
\hline & & Shigella_1B_R & GGA AGT GAC AGG GCA TTT GTG GAT & & & \\
\hline \multicolumn{7}{|c|}{ Salmonella spp. } \\
\hline & Sdf I & Salmonella_sdf1_FW & TGT GTT TTA TCT GAT GCA AGA GG & 53 & 304 & {$[25,26]$} \\
\hline & & Salmonella_sdf1_RW & TGA ACT ACG TTC GTT CTT CTG G & & & \\
\hline \multicolumn{7}{|c|}{ Vibrio cholera } \\
\hline & Vc & Vibrio_Vc_FW & GTTCGCGCTGGTGAAGGTTCA & 57 & 192 & [27] \\
\hline & & Vibrio_Vc_RW & TGGCATACCAGAGTCTTTCTGTG & & & \\
\hline \multicolumn{7}{|c|}{ Cryptosporidium spp. } \\
\hline & 18 s SSU rRNA locus & 18 s Morgan F & AGTGACAAGAAATAACAATACAGG & 60 & 298 & [28] \\
\hline & & $18 \mathrm{~s}$ Morgan R & CCTGCTTTAAGCACTCTAATTTTC & & & \\
\hline \multicolumn{7}{|l|}{ Giardia spp. } \\
\hline & gdh gene & GDHeF & TCAAGCTYAAYGCYGGYTTGCGT & 57 & 432 & [29] \\
\hline & & GDHiF & CAGTACAACTCYGCTCTCGG & & & \\
\hline & & GDHiR & GTTRTCCTTGCACATCTCC & & & \\
\hline
\end{tabular}

\section{Statistical analysis}

To examine associations between the presence or absence of diarrheal pathogen and risk factors within the different age groups $(<2$ or $\geq 2$ years) and different multiple infections in children, logistic regression was used. Residence location (rural or urban) was considered for their possible association with the occurrence of diarrheal pathogen infections. Descriptive statistics was done to calculate odds ratios and 95\% confidence intervals $(\mathrm{CI})$, and $\mathrm{p}$ values were used to infer statistical associations based on one-tailed $t$ test (Mantel-Haenszel Chi-square statistics) using free statistical software Epi-Info (http://www.openepi.com).

\section{Results}

In the present study, overall result showed the highest detection rate for diarrheagenic E. coli (DEC) followed by Rotavirus and Shigella spp. in cases with 
symptoms of diarrhea (Table 2). Besides DEC (30.7\%), the other pathogens with a decreasing order of detection rates were Rotavirus (26.15\%), Shigella (23.84\%), Adenovirus (4.61\%), Cryptosporidium (3.07\%), and Giardia (0.7\%). Different strains of DEC such as EPEC (21.53\%), STEC (10.76\%), EAEC (6.90\%), 0157 (4.61\%), and EHEC (0.77\%) were detected in the stool samples from cases. All these samples were negative for Salmonella spp. and Vibrio cholera. Surprisingly DEC, Shigella spp. and Adenovirus were also detected in 20.83, 4.61 , and $2.08 \%$ of the healthy control subjects, respectively (Table 2). Representative gel image and immunochromatographic test positive strips are shown in Additional file 1.

Among the control subjects for which DEC was detected, the majority had infections with EPEC (10.41\%) followed by STEC (6.25\%), EAEC (2.08\%), and O 157 $(2.08 \%)$. No healthy subject was detected with Rotavirus, Giardia, Cryptosporidium spp., Salmonella spp., and Vibrio spp. The pathogen detection rates for cases and controls for each pathogen category are statistically analyzed which showed a significantly higher detection rate for Shigella spp $(p=0.0086)$ and Rotavirus $(p=0.0135)$, whereas the differences were not significant for rest of the detected pathogens.

Gender-wise distributions of diarrheal incidences for different etiological agents are shown in Table 3. The total detection rate for at least one infectious etiology among the cases with acute diarrhea was slightly lower in male patients $(54.28 \%)$ than in female patients $(60 \%)$. Only Rotavirus detection was significantly higher among male cases $(p=0.0003)$. Among all the cases with diarrhea, detection rate of DEC was slightly higher among males
(31.42\%) compared to females (30\%). Cryptosporidium, Shigella, and Giardia were also detected with relatively higher rate in males compared to females. However, Adenovirus detection rate was moderately higher among females though the difference was not significant on statistical analysis.

Among cases with diarrhea, at least one infectious etiology was detected in 24 of $40(60 \%)$ children living in rural settings in comparison to 50 of 90 (55.55\%) children from urban settings. Adenovirus was more prevalent in rural children $(p=0.026)$ (Table 4). Cryptosporidium was also detected with higher rate among rural children when compared to urban ones ( $p=0.02623)$. Though DEC was also detected predominantly in rural children, the difference however was not significant $(p>0.05)$. Among DEC, only STEC was found significantly higher $(p=0.014)$ in rural children (Additional file 2). In contrast, Rotavirus was more prevalent in urban children $(p=0.027)$. Shigella and Giardia detection rates were only slightly higher among the urban in comparison to rural children but not statistically significant $(p>0.05)$.

The data on age group ( $<2$ years, and $2-5$ years)-wise distribution of various etiological agents in children presenting with symptoms of acute diarrhea are depicted in Table 5. We observed that Rotavirus, Shigella, and DEC were the three major etiological agents detected in children under both the age groups. Cases positive for at least one infectious etiology were higher among children $<2$ years of age $(58.53 \%)$ in comparison to those between 2 and 5 years $(54.16 \%)$ which was not significant though $(p>0.05)$. Of all etiologies, only Rotavirus infection was found significantly associated with children under $<2$ years age group $(p=0.003)$.

Table 2 Frequencies of detection of etiological agents causing diarrhea in children

\begin{tabular}{|c|c|c|c|c|}
\hline \multirow[t]{2}{*}{ Infectious agent detected } & \multirow[t]{2}{*}{ Method of detection } & \multicolumn{2}{|c|}{ Frequency (\%) of detection in } & \multirow[t]{2}{*}{$p$ value } \\
\hline & & Diarrheal group $(n=130)$ & Non-diarrheal group $(n=48)$ & \\
\hline $\mathrm{DEC}^{\mathrm{a}}$ & PCR & $40(30.7)$ & $10(20.83)$ & 0.1935 \\
\hline STEC & PCR & $14(10.76)$ & $3(6.25)$ & 0.3685 \\
\hline EPEC & PCR & $28(21.53)$ & $5(10.41)$ & 0.0975 \\
\hline EHEC & $P C R$ & $1(0.77)$ & 0 & 0.9434 \\
\hline EAEC & PCR & $9(6.9)$ & $1(2.08)$ & 0.2412 \\
\hline O 157 & PCR & $6(4.61)$ & $1(2.08)$ & 0.4525 \\
\hline Shigella spp. & PCR & $31(23.84)$ & $2(4.16)$ & $0.0086^{*}$ \\
\hline Rotavirus $^{b}$ & Immunochromatography & $34(26.15)$ & 0 & $0.0135^{*}$ \\
\hline Adenovirus $^{\mathrm{b}}$ & Immunochromatography & $6(4.61)$ & $1(2.08)$ & 0.4525 \\
\hline Cryptosporidium spp. & PCR & $4(3.07)$ & 0 & 0.4091 \\
\hline Giardia spp. & PCR & $1(0.77)$ & 0 & 0.3652 \\
\hline
\end{tabular}

* Statistically significant

a DEC includes all detected strains of diarrheagenic E. coli. Each of those strains were diagnosed using strain-specific primers as recommended in the previously published reports (see details as shown in Table 1)

b Rotavirus and Adenovirus were detected by Immunochromatography test using commercially procured kit (Combi-Strip C-1004, Coris Bioconcept Itd-Belgium) 
Table 3 Gender-wise distribution of incidences of infectious etiologies of diarrhea in children

\begin{tabular}{|c|c|c|c|c|c|c|c|}
\hline \multirow[t]{2}{*}{ Total no of samples } & \multirow{2}{*}{$\begin{array}{l}\text { Total no. with an } \\
\text { infectious diagnosis }\end{array}$} & \multicolumn{6}{|c|}{ No (\%) of cases tested positive for different etiologies } \\
\hline & & Cryptosporidium & Adenovirus & Rotavirus* & Shigella stx & Giardia & DEC \\
\hline \multicolumn{8}{|l|}{ Male } \\
\hline 70 & $38(54.28)$ & $3(4.28)$ & $2(2.85)$ & $28(40)$ & $20(28.57)$ & $1(1.42)$ & $22(31.42)$ \\
\hline \multicolumn{8}{|l|}{ Female } \\
\hline 60 & $36(60)$ & $1(1.66)$ & $4(4.66)$ & $6(10)$ & $11(18.33)$ & $0(0)$ & $18(30)$ \\
\hline \multicolumn{8}{|l|}{ Statistics } \\
\hline$p$ value & 0.5121 & 0.406 & 0.3158 & 0.0003 & 0.1749 & 0.5589 & 0.8604 \\
\hline $\begin{array}{l}\text { 95\% Cl (lower, } \\
\text { upper) }\end{array}$ & $0.3937,1.5919$ & $0.2675,26.0903$ & $0.0727,2.3316$ & $2.2755,15.8209$ & $0.7734,4.1051$ & $0.1044,65.3068$ & $0.5062,2.2595$ \\
\hline Odds ratio & 0.7917 & 2.642 & 0.4118 & 6 & 1.7818 & 2.6115 & 1.0694 \\
\hline
\end{tabular}

Percentages are calculated based on the total number of male and female cases with symptoms of diarrhea as included in the present study $(n=70$ and 60 , respectively)

DEC diarrheagenic Escherichia coli

* Statistically significant

Table 4 Location-wise distribution of incidences of infectious etiologies of diarrhea

\begin{tabular}{|c|c|c|c|c|c|c|c|}
\hline \multirow[t]{2}{*}{ Total no of samples } & \multirow{2}{*}{$\begin{array}{l}\text { Total no. with an infec- } \\
\text { tious diagnosis }\end{array}$} & \multicolumn{6}{|c|}{ No $(\%)$ of cases tested positive for different etiologies } \\
\hline & & Cryptosporidium* & Adenovirus* & Rotavirus* & Shigella stx & Giardia & DEC \\
\hline \multicolumn{8}{|l|}{ Rural } \\
\hline 40 & $24(60)$ & $3(7.5)$ & $4(10)$ & $6(15)$ & $9(22.5)$ & $0(0)$ & $16(40)$ \\
\hline \multicolumn{8}{|l|}{ Urban } \\
\hline 90 & $50(55.55)$ & $1(1.11)$ & $2(2.22)$ & $28(31.11)$ & $22(24.45)$ & $1(1.11)$ & $24(26.66)$ \\
\hline \multicolumn{8}{|l|}{ Statistics } \\
\hline P value & 0.3190 & $0.02623^{*}$ & $0.0260^{*}$ & $0.0273^{*}$ & 0.4055 & 0.2525 & 0.0650 \\
\hline 95\% Cl (lower, upper) & $48.33,65.12$ & $0.9403,7.907$ & $1.921,9.915$ & $19.33,34.34$ & $17.3,31.89$ & $0.0,4.657$ & $23.46,39.18$ \\
\hline Odds ratio & 1.2 & 7.216 & 4.889 & 0.3908 & 0.8974 & 0 & 1.833 \\
\hline
\end{tabular}

Percentages are calculated based on the total number of rural and urban children with symptoms of diarrhea as included in the present study $(n=40$ and 90 , respectively)

DEC diarrheagenic Escherichia coli

* Statistically significant

Table 5 Age group-wise distribution of incidences of different etiological agents causing diarrhea in children in diarrheal group

\begin{tabular}{|c|c|c|c|c|}
\hline & \multicolumn{2}{|c|}{ No (\%) of cases under age groups } & \multicolumn{2}{|c|}{ Statistical analysis } \\
\hline & $<2$ years $(n=82)$ & $2-5$ years $(n=48)$ & $p$ value & Odds ratio $(95 \% \mathrm{Cl})$ \\
\hline At least one infectious etiology & $48(58.53)$ & $26(54.16)$ & 0.316 & $1.195(0.582,2.449)$ \\
\hline$D E C$ & $22(26.82)$ & $18(37.49)$ & 0.106 & $0.611(0.285,1.309)$ \\
\hline Shigella flexneri & $20(24.39)$ & $11(22.91)$ & 0.429 & $1.085(0.468,2.515)$ \\
\hline Rotavirus & $28(34.14)$ & $6(12.49)$ & $0.003^{* *}$ & $3.63(1.377,9.57)$ \\
\hline Adenovirus & $2(2.43)$ & $4(8.33)$ & 0.079 & $0.275(0.048,1.562)$ \\
\hline Cryptosporidium & $4(4.87)$ & 0 & 0.076 & Undefined\# \\
\hline Giardia & $1(1.21)$ & 0 & 0.315 & Undefined\# \\
\hline
\end{tabular}

Percentages are calculated based on the total number of children with symptoms of diarrhea under $<2$ years and $2-5$ years age groups ( $n=82$ and 48 , respectively)

** Extremely statistically significant 
Among the different DEC strains, EPEC was detected significantly higher in $<2$ years children in comparison to $>2$ years age group $(\mathrm{p}=0.001)$ (Table 6$)$, while no significant differences were observed on detection rates of STEC and EAEC when compared between the above two age groups. Moreover, E. coli O157 was detected with higher frequency among <2-year-old children, although statistically not significant $(p<0.28)$. Cryptosporidium,

Table 6 Age group-wise distribution of incidences of different strains of Diarrheagenic $E$. coli causing diarrhea in children

\begin{tabular}{|c|c|c|c|c|}
\hline & \multicolumn{2}{|c|}{$\begin{array}{l}\text { No (\%) of cases under age } \\
\text { groups }\end{array}$} & \multicolumn{2}{|c|}{ Statistical analysis } \\
\hline & $\begin{array}{l}<2 \text { years } \\
(n=22)\end{array}$ & $\begin{array}{l}2-5 \text { years } \\
(n=18)\end{array}$ & $p$ value & Odds ratio $(95 \% \mathrm{Cl})$ \\
\hline STEC & $7(31.81)$ & $7(38.88)$ & 0.328 & $0.733(0.198-2.704)$ \\
\hline EPEC & $20(90.9)$ & $8(44.44)$ & $0.001^{* *}$ & $12.5(2.226-70.18)$ \\
\hline EHEC & $1(4.54)$ & 0 & 0.275 & Undefined\# \\
\hline 0157 & $4(18.18)$ & $2(11.11)$ & 0.288 & $1.778(0.286-1.04)$ \\
\hline EAEC & $5(22.72)$ & $4(22.22)$ & 0.635 & $1.56(0.243-10.03)$ \\
\hline
\end{tabular}

Percentages are calculated based on the total number of children with symptoms of diarrhea with detection of DEC under $<2$ years and $2-5$ years age groups ( $n=22$ and 18 , respectively)

** Extremely statistically significant
Giardia, and E. coli $\mathrm{O} 157$ were observed more predominantly in children $>1$ year of age (data not shown).

The detection rates and their distribution among each individual pathogen type (only a single pathogen detection) comparing cases and controls are shown in the bar graphs as in Fig. 1. There was a significantly higher rate of detection only for Rotavirus mono-infection among cases with diarrhea in comparison to the controls $(p=005014)$. Also the overall rate of detection of a single infection only was significantly higher among cases in comparison to control subjects $(p=0.0268)$.

In this study, we observed many children infected with multiple pathogens, and the detection rates under different combinations of concurrent infections are presented in Table 7. Overall result showed simultaneous detection of two or more pathogens in $30 \%$ of cases included in this study. Of a total 44 cases with co-infections, 33 had double infections, 10 had triple infection, and only 1 had infection with more than three pathogens concurrently. Surprisingly, in case of control group of 48 children with no diarrhea, co-infections were detected in 3 (6.25\%) children.

An overall analysis showed statistically significant differences between detection rates for combinations of two infections concurrently among cases vs controls $(p=0.004915)$. Co-infection of Rotavirus with Shigella was the most frequent combination, which was detected

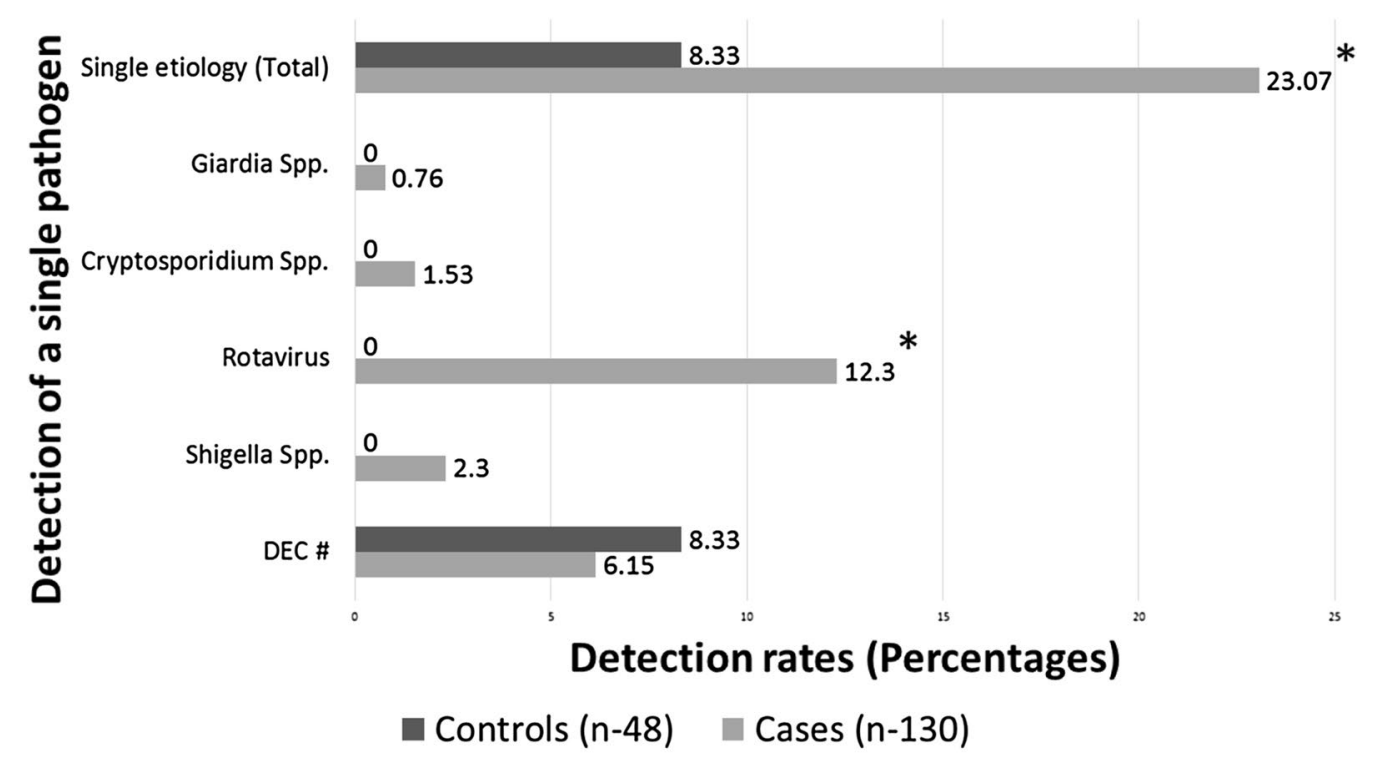

Fig. 1 Bar graphs showing detection rates of infections with a single etiological agent among children presenting with diarrhea in comparison to non-diarrheal controls. In a $2 \times 2$ table analysis for comparison of proportions between cases and controls for cases with detection of a single infection, all expected values (row total X column total/grand total) were $\geq 5$. So Chi-square analysis was recommended. Two-tailed $p$ value by Mantel-

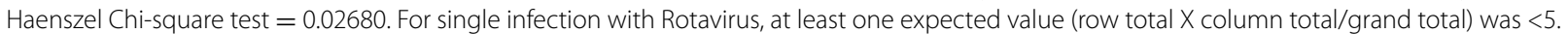
So Mid-P exact test was recommended rather than Chi-square (http://www.openepi.com). Two-tailed $p$ value by Mid-P exact test $=0.005014$. *Statistically significant.\# DEC: any strain of diarrheagenic E. coli 
Table 7 Co-infection combinations with two or more infectious etiologies detected in diarrheagenic group vs controls

\begin{tabular}{|c|c|c|c|}
\hline Combinations of pathogens & $\begin{array}{l}\text { Frequency (\%) of detection } \\
\text { cases }(n=130)\end{array}$ & $\begin{array}{l}\text { Frequency }(\%) \text { of detection } \\
\text { controls }(n=48)\end{array}$ & Statistical analysis \\
\hline \multicolumn{4}{|l|}{ Double infections } \\
\hline Shigella+STEC & $5(3.84)$ & 0 & \multirow{15}{*}{$\begin{array}{l}\text { Two-tailed } p \text { value by Mantel-Haenszel Chi- } \\
\text { square test }=0.004915^{*}\end{array}$} \\
\hline Shigella+EPEC & $3(2.3)$ & 0 & \\
\hline Cryptosporidium+EPEC & $1(0.76)$ & $1(2.08)$ & \\
\hline EPEC+O157 & $1(0.76)$ & $1(2.08)$ & \\
\hline Rotavirus+Shigella & $7(5.38)$ & 0 & \\
\hline Adenovirus+EPEC & $2(1.53)$ & 0 & \\
\hline Adenovirus+Cryptosporidium & $1(0.76)$ & 0 & \\
\hline Rotavirus+EPEC & $6(4.61)$ & 0 & \\
\hline Shigella+0157 & $2(1.53)$ & 0 & \\
\hline Shigella +EAEC & $2(1.53)$ & 0 & \\
\hline Adenovirus+EAEC & $1(0.76)$ & 0 & \\
\hline Rotavirus+EAEC & $1(0.76)$ & 0 & \\
\hline EPEC+EAEC & $2(1.53)$ & 0 & \\
\hline EPEC+STEC & 0 & $1(2.08)$ & \\
\hline Double infection (total) & $33(25.38)$ & $3(6.25)$ & \\
\hline \multicolumn{4}{|l|}{ Triple infections } \\
\hline Shigella+STEC+EPEC & $2(1.53)$ & 0 & \multirow{10}{*}{$\begin{array}{l}\text { Two-tailed } p \text { value by Mid-P exact } \\
\text { test }=0.03917^{*}\end{array}$} \\
\hline EPEC+EHEC+O157 & $1(0.76)$ & 0 & \\
\hline Rotavirus+Shigella+STEC & $2(1.53)$ & 0 & \\
\hline Rotavirus+Cryptosporidium+EPEC & $1(0.76)$ & 0 & \\
\hline Rotavirus+Shigella+EPEC & $1(0.76)$ & 0 & \\
\hline Rotavirus+Shigella+EPEC & $1(0.76)$ & 0 & \\
\hline Shigella+STEC+EPEC & $1(0.76)$ & 0 & \\
\hline Adenovirus+Shigella +EPEC & $1(0.76)$ & 0 & \\
\hline $\mathrm{EAEC}+\mathrm{O} 157+\mathrm{EAEC}$ & $1(0.76)$ & 0 & \\
\hline Triple infection (total) & $10(7.69)$ & 0 & \\
\hline $\begin{array}{l}\text { Adenovirus+Shigella+STEC+EPEC } \\
+ \text { +O157+EAEC }\end{array}$ & $1(0.76)$ & 0 & $\begin{array}{l}\text { Two-tailed } p \text { value by Mid-P exact } \\
\text { test }=0.7303\end{array}$ \\
\hline
\end{tabular}

Statistical analysis is shown considering only total number of cases and control subjects and respective co-isolation rates (double, triple, or more than three infections). In a $2 \times 2$ table analysis for comparison of proportions between cases and controls for double infections group, all expected values (row total $X$ column total/grand total) were $\geq 5$. So Chi-square analysis was recommended. For triple infections group and more than three infections one, at least one expected value (row total X column total/grand total) was $<5$. So Mid-P exact test was recommended rather than Chi-square (http://www.openepi.com)

$n$ total number of subjects

* Statistically significant

in $5.38 \%$ cases, followed by Rotavirus with EPEC (4.61\%) and Shigella with STEC (3.84\%). Co-infections with detection of two pathogens were detected in one healthy control child each with the following combinations, viz., EPEC with Shigella, EPEC with STEC, and EPEC with O 157.

Overall analysis also showed statistically significant differences between detection rates for combinations of three infections concurrently among cases vs controls $(p=0.03917)$. There were two cases each under the following combinations with triple infection: (1) Rotavirus and Shigella with STEC; (2) Shigella and STEC with
EPEC. Other combinations of triple infections were detected only in one child in each combination of concurrent infections (Table 7).

Age group-wise distributions of mono-infections and multiple infections are shown in Fig. 2. Of the total 30 cases with detection of a single infection, there was a predominance under the younger age group ( $<2$ years) children. Similar observation was recorded in case of multiple infections where majority was detected in the younger age group. There was no statistical difference when mono- and multiple infections were analyzed vs two age groups ( $<2$ years and $2-5$ years). 


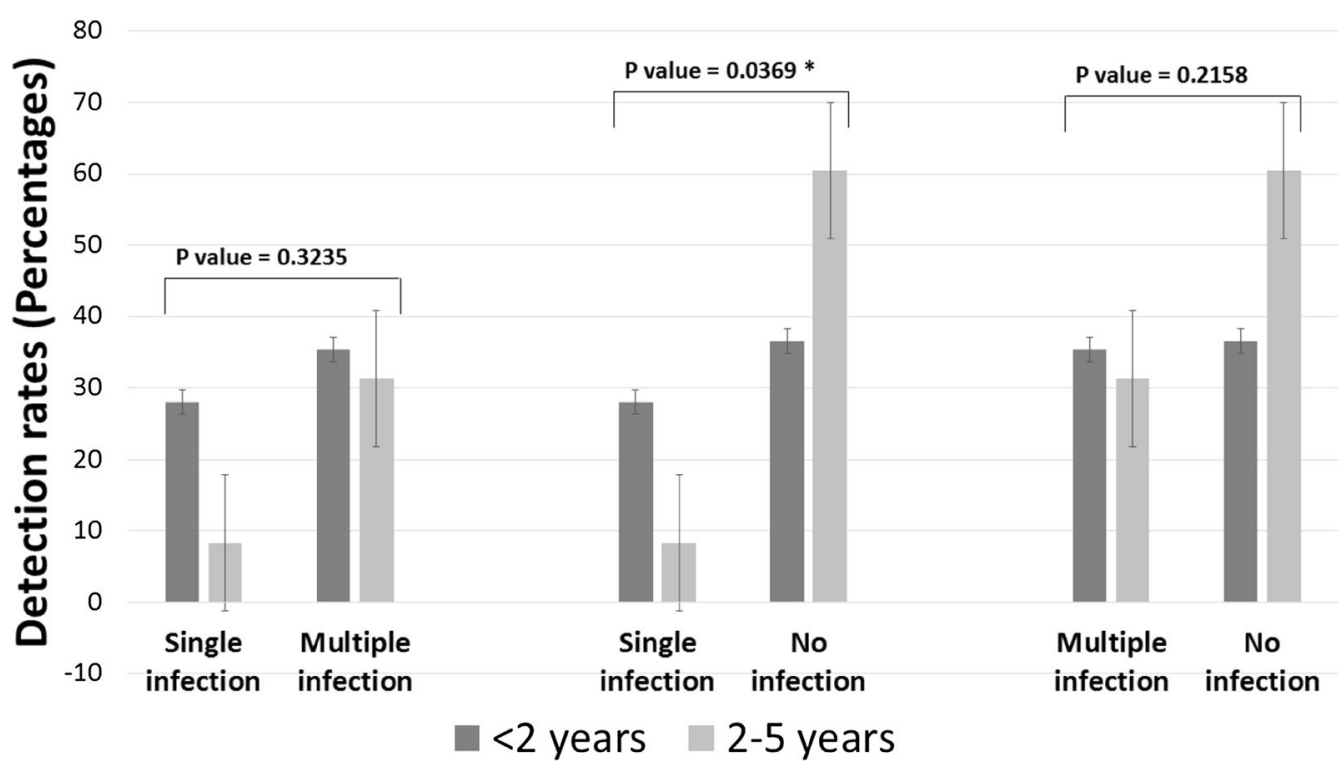

Fig. 2 Bar graphs comparing detection rates of mono-infections and co-infections among children of different age groups. Data were analyzed considering the cases with no infectious agent detection as control groups (30 cases under <2 years age group, and 26 cases under 2-5 years age group). In $2 \times 2$ table analysis for comparison of proportions between cases with detection of single/multiple infections in both age groups, all expected values (row total $X$ column total/grand total) were $\geq 5$. So Chi-square analysis was recommended. Two-tailed $p$ value by Mantel-Haenszel Chi-square test $=0.0369$ for single infections. Two-tailed $p$ value was 0.2158 for multiple infections. When the data were compared between singe vs multiple infections under both age groups, the two-tailed $p$ value was 0.3235 . ${ }^{*}$ Statistically significant

When data were analyzed considering the cases with no infectious agent detection as control groups (30 cases under $<2$ years age group, and 26 cases under 2-5 years age group), two-tailed $p$ value by Mantel-Haenszel Chisquare test $=0.0369$ for single infections showed a significant difference between the two age groups for single infection.

Overall data on disease severity (only in terms of numbers of liquid motions per day) compared between two groups, i.e., cases with detection of single infection vs cases with detection of more than one infections, are presented in Table 8. Two-sample independent $t$ test analysis revealed significantly higher number of motions per day among cases with multiple infections compared to those with single infection based on both equal variance $(p=0.001015)$ and unequal variance $(p=0.006885)$.
Other major associated symptoms were vomiting (46\%) and fever (23\%); when the symptoms were correlated with the test positivity for different etiologies, majority of cases positive for Shigella and Rotavirus had vomiting (29\%) and fever (27\%) (data not shown).

\section{Discussion}

Infectious diarrhea is a frequent problem in low-income countries which is a leading cause of death among children under 5 years of age [3]. Though many different types of agents are reported to be associated with infectious diarrhea, DEC has however been known to be the most commonly diagnosed etiology in India [30]. The overall result in our study showed that $56.92 \%$ of the children with diarrhea were diagnosed to be positive for at least one infectious etiology among the children with

Table 8 Comparison of the role of single infection vs multiple infections on average motions per day

\begin{tabular}{llllll}
\hline & $\mathbf{n}$ & No. of motions/day (min-max) & Mean average no & SD & Two-sample independent $\mathbf{t}$ test \\
\hline Single infection & 30 & $2-30$ & 10.71 & 12.6 & Equal variance $(0.001015)^{* *}$ \\
More than one infections & 44 & $12-25$ & 17.5 & 3.2 & Unequal variance $(0.006885)^{* *}$ \\
\hline
\end{tabular}

$n$ total number of cases

min minimum, max maximum

Two-sample independent $t$ test using OpenEpi (Version 3), open source calculator revealed significantly higher number of motions per day among cases with multiple infections compared to those with single infection based on both equal variance $(p=0.001015)$ and unequal variance $(p=0.006885)$

** Statistically extremely significant 
diarrhea. A study in the past showed E. coli (different strains) to be responsible for as much as $25 \%$ of all diarrheal diseases in developing countries [31]. In this study, we also found DEC to be the most common diarrheal agent in the study population.

In the diarrheal group, more than 1 infectious agent was diagnosed in $44(33.84 \%)$ cases. In our study, we found Rotavirus+Shigella to be the most frequent coinfection combination, while a previous study from Leon Nicaragua reported EAEC along with EPEC to be the most frequent co-infection [23].

The number of males suffering with diarrheal diseases was slightly more in comparison to females, which is similar to another study from India [30]. Our study showed that at least one infectious etiology in diarrhea is more frequently detected among children living in rural settings than urban settings. This may be due to the poor hygiene and sanitation conditions of rural population that posses a high risk of infection among children as recommended earlier.

In this study, the major etiological agent was identified to be DEC followed by Rotavirus and Shigella in the age group of $<2$ years. Study elsewhere showed DEC being responsible for acute diarrhea in 30-40\% of the affected children [31]. EPEC, EAEC, and ETEC were the most common strains of $E$. coli detected in diarrheal diseases as reported elsewhere [23]. In our study, EPEC was found more frequent than other DEC pathotypes, while in other studies EAEC was detected more frequently [32]. Few studies have also highlighted the role of Shigella as an important etiological agent for diarrheal disease [33, 34]. In our study, we observed that Shigella was responsible for $23.84 \%$ of infection in children with acute diarrhea.

Rotavirus infection was associated with substantial hospitalization and deaths among children [7]. In our study, we observed Rotavirus as the second leading cause of childhood diarrhea. Rotavirus was also present as multiple mixed infections with other diarrheal pathogens. Previously in a study from China, co-occurrence of Rotavirus and Sapovirus, Astrovirus, ETEC, or Campylobacter jejuni was observed in children [35]. In this Chinese study, co-infections between pathogens were found to be common; especially the two pairs, Rotavirus and Adenovirus, and Norovirus GII and Salmonella were reported to be positively associated with diarrhea.

Cryptosporidium and Giardia were shown to affect children younger than five years of age in India [36]. In this study, we observed that $4.61 \%$ of diarrheal cases were due to Cryptosporidium and $0.77 \%$ of cases ware due to Giardia. Giardia lamblia was not significantly associated with diarrhea in a study from Bangladesh [37].

Few studies from Africa have reported that almost one-third of studied children were infected with bacterial pathogens and about ten percent of them were co-infections [17, 38]. In our study, we observed that about $65.90 \%$ of cases have multiple infection in children $<2$ years of age. We could not observe any statistical significance among mono-infections and multiple infections with respect to age group between $<2$ years of age and $2-5$ year age group $(p=0.32)$. A recent study from China reported viral-bacterial co-infection in $<5$-yearold children [35]. In our study, we observed several mixed infections such as DEC with Shigella, Rotavirus with EPEC, and Rotavirus with Shigella. We observed that especially with Rotavirus and Adenovirus co-infections there was an increase in the diarrheal episodes per day.

Rotavirus co-infection with other enteric bacterial and protozoan pathogens was reported previously [39]. In our study, mixed infections of Cryptosporidium with Rotavirus, Adenovirus, and EPEC were observed. Cryptosporidium infection was more frequently observed in $<2$ year age group in comparison to $2-5$ year age group, although this was not statistically significant. We could not observe any association between Cryptosporidium infection along with vomiting and fever in the infected individuals. A synergistic effect between Rotavirus and other co-infecting pathogen(s) on diarrheal disease was also reported from a Latin American study [21].

Most studies of the causes of diarrhea in low-income and middle-income countries have looked at severe disease in people presenting for care, and there are few estimates of pathogen-specific diarrheal burdens in the community. In a recent cohort study, a substantial heterogeneity in pathogen-specific burdens of diarrhea was identified where the most important determinants were revealed to be age, geography, season, vaccine usage, and symptoms [40]. Community screening was beyond scope of the present study. However, considering disease severity to be the most important criteria to access the possibility of a synergistic effect due to mixed infection in childhood diarrhea, in our study we could note an increased frequency of diarrheal episodes in cases that were diagnosed to have multiple infectious etiologies. A recent study from China also supports the above fact where virus-bacteria and virus-parasite co-infections are the aggravating factors of severe diarrhea in children [39].

There are limited number of studies in India, which can really enlighten on acute childhood diarrhea and far lesser in number when it comes to its bacterial enteropathogenesis. However, $E$. coli has been recorded as the predominant bacteria followed by Shigella, Salmonella, Klebsiella, and Campylobacter [29]. A study from Bangladesh identified C. jejuni, ETEC, Shigella spp., and V. cholerae $\mathrm{O} 1$ as major bacterial pathogens that are significantly associated with diarrhea [37], while in our study 
EPEC and Shigella were found to be the most common diarrheal etiological agents.

Earlier studies support increased severity of diarrhea in the presence of Rotavirus-E. coli co-infection [41, 42]. Simultaneous interaction of Rotavirus and E. coli or Rotavirus and Shigella results in a greater risk of having diarrhea than would be expected if the co-infected organism acted independently of one another [21]. Similar coinfection patterns of Rotavirus with E. coli and Rotavirus with Shigella were observed most predominately in our study population. Shigella along with several other types of bacteria has been shown to have a recycling mechanism for their peptidoglycan, which is designed to prevent its release and interact with Nod1 [43]. In our study we found Shigella infection with different other diarrheal bacterial pathogens that may be the possible reason for disease severity in the patients.

At cellular and molecular level, diarrhea is simply an altered movement of ions and water. Enteric pathogens however can alter this balance towards net secretion. Together, co-infection might cause more severe diarrhea than infection with either pathogen alone [42]. Specific co-infecting pathogens might also act synergistically resulting in even greater pathogenesis and a large contribution to an overall diarrheal disease burden. In our study, we found high prevalence of co-infection similar to the other studies reported previously [41-44]. Rotavirus is mainly responsible for decreased absorption without any significant intestinal inflammation, Shigella species causes inflammatory and invasive diarrhea and EPEC alters the intestinal epithelial integrity [43]. We observed several mixed infections with all these three pathogens. On an average $>10$ diarrheal episodes/day in cases with concurrent infections might be due to an aggravated effect and a number of cellular mechanisms activated simultaneously by various pathogen factors. A true understanding of pathogenesis of diarrheal disease is incomplete without the thorough understanding of biological connections of these pathogens and synergistic interaction between co-infecting pathogens. We may be able to improve our understanding of the pathogenic potential of enteric infection consistently by distinguishing between single and mixed infection.

It is also important to include healthy controls in order to compare the distribution of exposure in healthy controls compared to cases as recommended elsewhere [35]. The overall result in our study showed that $20.83 \%$ cases in non-diarrheal children also had at least one infectious agent as detected in the stool specimens. Reports originated from other studies also showed the detection of some of those agents in stool samples from human subjects with no symptoms of diarrhea $[25,26]$. In the non-diarrheal group, only 3 (6.25\%) subjects were found positive for multiple infections. However, it is not clear why those apparently normal individuals had the infectious agents but no symptoms of diarrhea was noticed. However, the frequency of detection of any diarrheal infectious agent or multiple agents in these apparently healthy subjects were much less, compared to those in case of the symptomatic subjects as supported on statistical analysis.

The overall finding on a broad spectrum of etiological agents of diarrhea and different combinations of concurrent infections in the pediatric patients will probably aid in planning future studies on various aspects of diarrheal diseases in this population. It is hypothesized that in cases with concurrent infections, different combinations of etiological agents might be complementing each other's strategies of pathogenesis resulting in an increased disease severity, and other complications, which is a matter of concern.

\section{Conclusion}

This hospital-based study highlighted the overall burden of major bacterial, viral, and protozoan parasites in childhood diarrhea in the study region where multiple infections in nearly one-third of the cases pose a significant question to understand the synergistic role contributed by each associated pathogen in the overall pathogenesis of diarrheal diseases. Nevertheless, the results suggested that DEC strains such as EPEC and STEC, which are normally not screened routinely, should also be suspected in childhood diarrhea. Suspecting possible multiple infectious etiologies and diagnosis of the right causative agent(s) can help in a better pharmacological management of acute childhood diarrhea. Also it is recommended to address the issues of combined pathologies of co-existing diarrheagenic agents in experimental infection studies.

\section{Additional files}

Additional file 1. Additional figures.

Additional file 2. Additional tables.

\section{Abbreviations}

Cl: confidence interval; DEC: diarrheagenic Escherichia coli; EPEC: enteropathogenic Escherichia coli; EHEC: enterohemorrhagic Escherichia coli; STEC: shiga toxin-producing Escherichia coli; EAEC: enteroaggregative Escherichia coli; PCR: polymerase chain reaction; WHO: World Health Organization.

\section{Authors' contributions}

PSS, SK, and AKS designed the study. NKM was key in classifying cases and gathered patients' clinical history and other relevant information. AKS collected specimens and performed the tests. NKM and PSS contributed to the patients' diagnoses. AKS, SK, and PSS interpreted data and wrote the manuscript. MS did critical review of the manuscript. All authors read and approved the final manuscript. 


\section{Author details}

${ }^{1}$ Infection Biology Laboratory, School of Biotechnology, KIIT University, Bhubaneswar, Odisha 751024, India. ${ }^{2}$ Kalinga Institute of Medical Sciences, KIIT University, Bhubaneswar, Odisha 751024, India. ${ }^{3}$ Divisions of Pathology, School of Medicine, International Medical University, 57000 Kuala Lumpur, Malaysia.

\section{Acknowledgements}

The authors duly acknowledge Dr. Jyotiprakash Mishra (pediatrician) for his kind assistance in patient identification and sample collection. Authors are also thankful to Miss. Swagatika Panda for her help in the laboratory. The kind gift of standard Cryptosporidium genomic DNA from Prof. Gagandeep Kang, Christian Medical College, Vellore (India) is greatly acknowledged. We are also thankful to Prof. Adrian Hehl, Institute of Parasitology, University of Zurich for providing us the standard genomic DNA of Giardia used in this study.

\section{Competing interests}

The authors declare that they have no competing interests.

\section{Availability of data and materials}

Data will not be shared because the data generated out of patients contain personal information of the patients.

\section{Ethics approval and consent to participate}

All infants' parents provided written informed consent, and this study was approved by the Ethical Committee of Kalinga Institute of Medical Sciences, KIIT University.

\section{Funding}

This study was supported by KIIT University. The Cryptosporidium and Giardia diagnostic reagents were used from the fund granted by Bill and Melinda Gates Foundation through a supplemental fund transfer to KIIT University from the University of California, Davis via the London School of Hygiene \& Tropical Medicine under the Orissa Rural Sanitation Health Impact Trial (Registration No. NCT01214785).

\section{Publisher's Note}

Springer Nature remains neutral with regard to jurisdictional claims in published maps and institutional affiliations.

Received: 7 August 2016 Accepted: 27 March 2017

Published online: 11 April 2017

\section{References}

1. Walker CLF, Rudan I, Liu L, Nair H, Theodoratou E, Bhutta ZA, et al. Global burden of childhood diarrhoea and pneumonia. Lancet. 2013;381:1405-16.

2. Lakshminarayanan S, Jayalakshmy R. Diarrheal diseases among children in India: current scenario and future perspectives. J Nat Sci Biol Med. 2015;6:24.

3. Kotloff KL, Nataro JP, Blackwelder WC, Nasrin D, Farag TH, Panchalingam $S$, et al. Burden and aetiology of diarrhoeal disease in infants and young children in developing countries (the Global Enteric Multicenter Study, GEMS): a prospective, case-control study. Lancet. 2013;382:209-22.

4. Kotloff KL, Blackwelder WC, Nasrin D, Nataro JP, Farag TH, Van Eijk A, et al. The Global Enteric Multicenter Study (GEMS) of diarrheal disease in infants and young children in developing countries: epidemiologic and clinical methods of the case/control study. Clin Infect Dis. 2012;55:S232.

5. O'Ryan M, Prado V, Pickering LK. A millennium update on pediatric diarrheal illness in the developing world. Semin Pediatr Infect Dis. 2005;16:125-36.

6. Batabyal P, Mookerjee S, Sur D, Palit A. Diarrheogenic Escherechia coli in potable water sources of West Bengal, India. Acta Trop. 2013;127:153-7.

7. Kawai K, O'Brien MA, Goveia MG, Mast TC, El Khoury AC. Burden of rotavirus gastroenteritis and distribution of rotavirus strains in Asia: a systematic review. Vaccine. 2012;30(7):1244-54.

8. Livio S, Strockbine NA, Panchalingam S, Tennant SM, Barry EM, Marohn $M E$, et al. Shigella isolates from the global enteric multicenter study inform vaccine development. Clin Infect Dis. 2014;59:933-41.
9. Tate JE, Burton AH, Boschi-Pinto C, Steele AD, Duque J, Parashar UD. 2008 estimate of worldwide rotavirus-associated mortality in children younger than 5 years before the introduction of universal rotavirus vaccination programmes: a systematic review and meta-analysis. Lancet Infect Dis. 2012;12:136-41.

10. Tate JE, Burton AH, Boschi-Pinto C, Parashar UD. Global, regional, and national estimates of rotavirus mortality in children $<5$ years of age, 2000-2013. Clin Infect Dis. 2016;62:S96-105.

11. Langendorf C, Le Hello S, Moumouni A, Gouali M, Mamaty AA, Grais RF, et al. Enteric bacterial pathogens in children with diarrhea in Niger: diversity and antimicrobial resistance. PLOS ONE. 2015;10:1-18.

12. Bardhan P, Faruque ASG, Naheed A, Sack DA. Decrease in shigellosisrelated deaths without Shigella spp.-specific interventions, Asia. Emerg Infect Dis. 2010;16:1718-23.

13. Zhu JY, Duan GC, Yang HY, Fan QT, Xi YL. Atypical class 1 integron coexists with class 1 and class 2 integrons in multi-drug resistant Shigella flexneri isolates from China. Curr Microbiol. 2011;62:802-6.

14. Sarkar R, Tate JE, Ajjampur SSR, Kattula D, John J, Ward HD, et al. Burden of diarrhea, hospitalization and mortality due to cryptosporidial infections in Indian children. PLoS Negl Trop Dis. 2014;8:e3042.

15. Norhayati M, Fatmah MS, Yusof S, Edariah AB. Intestinal parasitic infections in man: a review. Med J Malays. 2003;58(2):296-305.

16. Gasparinho C, Mirante MC, Centeno-Lima S, Istrate C, Mayer AC, Tavira L, et al. Etiology of diarrhea in children younger than 5 years attending the Bengo General Hospital in Angola. Pediatr Infect Dis J. 2016;35:e28-34.

17. Bonkoungou IJO, Haukka K, Österblad M, Hakanen AJ, Traoré AS, Barro N, et al. Bacterial and viral etiology of childhood diarrhea in Ouagadougou, Burkina Faso. BMC Pediatr. 2013;13:36.

18. Sambe-Ba B, Espié E, Faye ME, Timbiné LG, Sembene M, Gassama-Sow A. Community-acquired diarrhea among children and adults in urban settings in Senegal: clinical, epidemiological and microbiological aspects. BMC Infect Dis. 2013;13:580.

19. Mukherjee AK, Chowdhury P, Rajendran K, Nozaki T, Ganguly S. Association between Giardia duodenalis and coinfection with other diarrhea-causing pathogens in India. Biomed Res Int. 2014. doi:10.1155/2014/786480.

20. Mladenova Z, Steyer A, Steyer AF, Ganesh B, Petrov P, Tchervenjakova $T$, et al. Aetiology of acute paediatric gastroenteritis in Bulgaria during summer months: prevalence of viral infections. J Med Microbiol. 2015;64:272-82.

21. Bhavnani D, Goldstick JE, Cevallos W, Trueba G, Eisenberg JNS. Synergistic effects between rotavirus and coinfecting pathogens on diarrheal disease: evidence from a community-based study in northwestern Ecuador. Am J Epidemiol. 2012;176:387-95.

22. Elhag WI, Saeed HA, Omer EFE, Ali AS. Prevalence of rotavirus and adenovirus associated with diarrhea among displaced communities in Khartoum, Sudan. BMC Infect Dis. 2013;13:209.

23. Vilchez S, Reyes D, Paniagua M, Bucardo F, Möllby R, Weintraub A. Prevalence of diarrhoeagenic Escherichia coli in children from León, Nicaragua. J Med Microbiol. 2009;58:630-7.

24. Paton AW, Paton JC. Detection and characterization of shiga toxigenic escherichia coli by using multiplex PCR assays for stx1, stx2, eaeA, enterohemorrhagic E. coli hlyA, rfb(O111), and rfb(O157). J Clin Microbiol. 1998;36:598-602.

25. de Freitas CG, Santana ÂP, da Silva PHC, Gonçalves VSP, Barros MD, Torres FA, et al. PCR multiplex for detection of Salmonella Enteritidis, Typhi and Typhimurium and occurrence in poultry meat. Int J Food Microbiol. 2010;139(15-22):26

26. Boschi-Pinto C, Velebit L, Shibuya K. Estimating child mortality due to diarrhoea in developing countries. Bull World Health Organ. 2008;86:710-7.

27. Hossain MT, Kim EY, Kim YR, Kim DG, Kong IS. Development of a groEL gene-based species-specific multiplex polymerase chain reaction assay for simultaneous detection of Vibrio cholerae, Vibrio parahaemolyticus and Vibrio vulnificus. J Appl Microbiol. 2013;114:448-56.

28. Morgan UM, Constantine CC, Forbes DA. Differentiation between human and animal isolates of Cryptosporidium parvum using rDNA sequencing and direct PCR analysis. J Parasitol. 1997:83:825-30.

29. Read CM, Monis PT, Thompson RCA. Discrimination of all genotypes of Giardia duodenalis at the glutamate dehydrogenase locus using PCRRFLP. Infect Genet Evol. 2004;4:125-30. 
30. Rathaur VK, Pathania M, Jayara A, Yadav N. Clinical study of acute childhood diarrhoea caused by bacterial enteropathogens. J Clin Diagn Res. 2014;8:PC01-5.

31. Niyogi SK, Saha MR, De SP. Enteropathogens associated with acute diarrhoeal diseases. Indian J Public Health. 1994;38:29-32.

32. Hegde A, Ballal MSS. Detection of diarrheagenic Escherichia coli by multiplex PCR. Indian J Med Microbiol. 2012;1:279.

33. Breurec S, Vanel N, Bata P, Chartier L, Farra A, Favennec L, et al. Etiology and epidemiology of diarrhea in hospitalized children from low income country: a matched case-control study in Central African Republic. PLoS Negl Trop Dis. 2016;10:e0004283.

34. George CM, Ahmed S, Talukder KA, Azmi IJ, Perin J, Sack RB, et al. Shigella infections in household contacts of pediatric shigellosis patients in rural Bangladesh. Emerg Infect Dis. 2015;21:2006-13.

35. Li LL, Liu N, Humphries EM, Yu JM, Li S, Lindsay BR, et al. Aetiology of diarrhoeal disease and evaluation of viral-bacterial coinfection in children under 5 years old in China: a matched case-control study. Clin Microbiol Infect. 2016;22:381.e9-16.

36. Daniels ME, Shrivastava A, Smith WA, Sahu P, Odagiri M, Misra PR, et al. Cryptosporidium and giardia in humans, domestic animals, and village water sources in rural India. Am J Trop Med Hyg. 2015;93:596-600.

37. Albert MJ, Faruque AS, Faruque SM, Sack RB, Mahalanabis D. Case-control study of enteropathogens associated with childhood diarrhea in Dhaka, Bangladesh. J Clin Microbiol. 1999;37(11):3458-64.

38. Nitiema LW, Nordgren J, Ouermi D, Dianou D, Traore AS, Svensson L, et al. Burden of rotavirus and other enteropathogens among children with diarrhea in Burkina Faso. Int J Infect Dis. 2011;15:e646.
39. Zhang SX, Zhou YM, Xu W, Tian LG, Chen JX, Chen SH, Dang ZS, Gu WP, Yin JW, Serrano EZX. Impact of co-infections with enteric pathogens on children suffering from acute diarrhea in southwest China. Infect Dis Poverty. 2016;5:64.

40. Platts-Mills JA, Babji S, Bodhidatta L, Gratz J, Haque R, Havt A, et al. Pathogen-specific burdens of community diarrhoea in developing countries: a multisite birth cohort study (MAL-ED). Lancet Glob Health. 2015;3:e564.

41. Hori H, Akpedonu P, Armah G, Aryeetey M, Yartey J, Kamiya H, et al. Enteric pathogens in severe forms of acute gastroenteritis in Ghanaian children. Pediatr Int. 1996;38:672-6.

42. Velázquez FR, Matson DO, Calva JJ, Guerrero ML, Morrow AL, CarterCampbell S, Glass RI, Estes MK, Pickering LK, Ruiz-Palacios GM. Rotavirus infection in infants as protection against subsequent infections. N Engl J Med. 1996;335(14):1022-8.

43. Hodges K, Gill R. Infectious diarrhea: cellular and molecular mechanisms. Gut Microbes. 2010;1(1):4-21.

44. Bodhidatta L, McDaniel P, Sornsakrin S, Srijan A, Serichantalergs O, Mason CJ. Case-Control Study of diarrheal disease etiology in a remote rural area in western Thailand. Am J Trop Med Hyg. 2010;83:1106-9.

\section{Submit your next manuscript to BioMed Central and we will help you at every step:}

- We accept pre-submission inquiries

- Our selector tool helps you to find the most relevant journal

- We provide round the clock customer support

- Convenient online submission

- Thorough peer review

- Inclusion in PubMed and all major indexing services

- Maximum visibility for your research

Submit your manuscript at www.biomedcentral.com/submit 